\title{
28 Research Square \\ The Density of Calretinin Striatal Interneurons Is Decreased in 6-OHDA-Lesioned Mice
}

\section{Sarah Petryszyn}

Florey Neuroscience Institutes

Lydia Saidi

CERVO Brain Research Center

Dave Gagnon

CERVO Brain Research Center

André Parent

CERVO Brain research Center

Martin Parent ( $\square$ Martin.Parent@fmed.ulaval.ca )

CERVO Brain Research Centre https://orcid.org/0000-0002-0868-1010

\section{Research Article}

Keywords: Basal ganglia, Parkinson's disease, Dopamine, Calcium binding protein, Nucleus accumbens, Striatum

Posted Date: April 16th, 2021

DOl: https://doi.org/10.21203/rs.3.rs-407660/v1

License: (c) (i) This work is licensed under a Creative Commons Attribution 4.0 International License.

Read Full License 


\section{Abstract}

Interneurons play a significant role in the functional organization of the striatum and some of them display marked plastic changes in dopamine-depleted conditions. Here, we applied immunohistochemistry on brain sections from 6-hydroxydopamine (6-OHDA) mouse model of Parkinson's disease and sham animals to characterize the regional distribution and the morphological and neurochemical changes of striatal interneurons expressing the calcium binding protein calretinin (CR). Two morphological subtypes of calretinin-immunostained (CR+) interneurons referred respectively as small and medium-sized $\mathrm{CR}+$ interneurons were detected in 6-OHDA and sham-lesioned animals. The small cells $(9-12 \mu \mathrm{m})$ prevail in the anterior and dorsal striatal regions; they stain intensely for CR and display a single slightly varicose and moderately arborized process. The medium-sized CR+ interneurons $(15-20 \mu \mathrm{m})$ are slightly more numerous than the small CR+ cells and rather uniformly distributed within the striatum; they stain weakly for CR and display 2-3 long, slightly varicose and poorly branched dendrites. The density of medium $\mathrm{CR}+$ interneurons is significantly decreased in the dopamine-depleted striatum (158 \pm 15 neurons $/ \mathrm{mm}^{3}$ ), when compared to sham animals ( $370 \pm 41$ neurons $/ \mathrm{mm}^{3}$ ), whereas that of the small-sized CR+ interneurons is unchanged $\left(174 \pm 46\right.$ neurons $/ \mathrm{mm}^{3}$ in 6-OHDA-lesioned striatum and $164 \pm 22$ neurons $/ \mathrm{mm}^{3}$ in sham-lesioned striatum). The nucleus accumbens is populated only by medium-sized CR+ interneurons, which are distributed equally among the core and shell compartments and whose density is unaltered after dopamine denervation. Our results provide the first evidence that the medium-sized striatal interneurons expressing low level of CR are specifically targeted by dopamine denervation, while the small and intensely immunoreactive $\mathrm{CR}+$ cells remain unaffected. These findings suggest that high expression of the calcium binding protein CR might protect striatal interneurons against an increase in intracellular calcium level that is believed to arise from altered glutamate corticostriatal transmission in Parkinson's disease.

\section{Introduction}

The striatum is chiefly composed of $\gamma$-amino-butyric acid (GABAergic) spiny projection neurons, but it also comprises a small proportion of aspiny local circuit neurons (Graveland and DiFiglia 1985; Gerfen and Bolam 2010; Kawaguchi et al. 1995). Despite their relatively low number - it reportedly ranges from $2-3 \%$ of the total neuronal population in rodents (Rymar et al. 2004; Oorschot 2013) to $15-20 \%$ in nonhuman primates (Graveland and DiFiglia 1985) - the aspiny interneurons occupy a crucial position in the striatal microcircuitry (Kawaguchi et al. 1995; Tepper et al. 2018) and are involved in several motor and psychiatric disorders (Ding et al. 2011; Kataoka et al. 2010b; Pisani et al. 2007). The role of interneurons in shaping and tuning striatal inputs and outputs is well recognized, but their exact function remains elusive, especially in pathological conditions.

In 6-OHDA-leasioned mice used as animal models of Parkinson's disease, degeneration of nigrostriatal dopaminergic axons has been shown to lead to a significant reduction of dendritic arborization and spine density of striatal projection neurons (Gagnon et al. 2017; Fieblinger et al. 2014; Suarez et al. 2014; Gomez et al. 2019). The number and chemical makeup of various types of striatal interneurons have also 
been shown to be altered following degeneration of dopamine afferent projections in humans (Huot et al. 2007), non-human primates (Petryszyn et al. 2016) and rodents (Unal et al. 2015; Ma et al. 2014; Mura et al. 2000). These changes are thought to result from altered striatal activity known to be regulated by glutamate and dopamine neurotransmission, as evidenced by the increase in corticostriatal excitatory input that follows striatal dopamine depletion in Parkinson's disease, a condition that may lead to a neurotoxic raise of intracellular calcium levels (Blandini et al. 1996). In that context, calcium binding proteins expressed by striatal cells, including calbindin, parvalbumin and calretinin (CR), are believed to play an important role by maintaining calcium homeostasis and exerting protective effect against increases in intracellular calcium level (Choi 2005; Mitchell et al. 1994; Lee et al. 2002; FigueredoCardenas et al. 1998). A similar phenomenon occurs at substantia nigra level where calbindin expressed by midbrain dopamine cells has been shown to be neuroprotective (German et al. 1992; Inoue et al. 2019).

The present study focuses on the fate of striatal interneurons that express $\mathrm{CR}$, a calcium-binding protein of the "EF- hand" family, in mice that underwent a lesion of the nigrostriatal dopamine pathway. The striatum of mice harbors two morphological subtypes of aspiny calretinin-immunostained (CR+) interneurons (Petryszyn et al. 2014). Neurons of the first type stain intensely for CR, are endowed with a small cell body $(9-12 \mu \mathrm{m})$ and a slightly varicose and moderately arborized process, and prevail in the anterior and dorsal sectors of the striatum. Neurons of the second type stain moderately for CR but outnumber those of the first type; they have a medium-sized cell body $(15-20 \mu \mathrm{m})$ with 2-3 long, slightly varicose, poorly branched dendrites and are uniformly scattered throughout the striatum, but slightly more abundant in its ventral sector. It should be mentioned that, based on neurochemical makeup, the existence of three morphological subtypes of $\mathrm{CR}+$ cells has recently been reported in the mouse striatum, each showing different size of cell bodies (Garas et al. 2018).

Previous studies in rats in which the nigrostriatal dopaminergic pathway has been lesioned by means of the neurotoxin 6-OHDA led to contradictory findings about the fate of the $\mathrm{CR}+$ striatal interneurons. Some studies reported a significant but transitory increase in the number of striatal CR+ neurons (Mura et al. 2000), but other investigations detected a permanent decrease of the same neuronal elements (Ma et al. 2014). Despite the fact that mice have become a widely used animal model to study various neurodegenerative conditions, including Parkinson's disease, no data are currently available on the effect of striatal dopamine depletion on CR+ striatal interneurons in any mouse model of Parkinson's disease. In the light of the paucity and conflicting nature of the data obtained in rats and because no information are currently available in mice, we undertook a detailed stereological study to determine the fate of the morphological subtypes of striatal CR+ interneurons in unilateral 6-OHDA-lesioned mice, a widely used animal model of Parkinson's disease

\section{Materials And Methods}

\section{Animals}


Brains were obtained from 8 C57BL/6 male mice of 3-month-old (Mus musculus; Charles River, QC, Canada). Animals were housed in a temperature-controlled room $\left(21-25^{\circ} \mathrm{C}\right)$ under a $12 \mathrm{~h}$ light/dark cycle and had free access to food and water. All protocols were approved by the Institutional Animal Care and Use Committee (Comité de Protection des Animaux de I'Université Laval, \# 2019-287/VRR-18-107) and all procedures involving animals and their care were made in accordance with the Canadian Council on Animal Care's Guide to the Care and Use of Experimental Animals (Ed2).

\section{6-OHDA unilateral injection}

Four mice received a unilateral 6-OHDA injection in the right medial forebrain bundle $(\mathrm{mfb})$ to lesion the dopaminergic striatal afferent projections. Thirty minutes before 6-OHDA injections, mice received an i.p. injection of desipramine $(25 \mathrm{mg} / \mathrm{Kg}$ ) diluted in saline $(0.9 \%)$ at a concentration of $2 \mathrm{mg} / \mathrm{mL}$. Mice were then anesthetized using $2 \%$ isoflurane and their heads were fixed in a stereotaxic apparatus. A hole was drilled and the following stereotaxic coordinates relative to bregma were aimed: antero-posterior $=-1.2$ $\mathrm{mm}$; mediolateral $=1.1 \mathrm{~mm}$; dorsoventral $=-5.0 \mathrm{~mm}$, corresponding to the $\mathrm{mfb}$, according to the mouse brain atlas of Franklin and Paxinos (1997). A glass micropipette containing a freshly prepared solution of 6-OHDA diluted in ascorbic acid (0.02\%) at a concentration of $6 \mu \mathrm{g} / \mu \mathrm{L}$ was slowly introduced in the mfb. The 6-OHDA was then pressure injected $(0.125 \mu \mathrm{L} / \mathrm{min}$, during $2 \mathrm{~min})$. Following injection, the micropipette was left in place for 2 min before being slowly retracted. A total volume of $0.25 \mu \mathrm{L}$ of 6OHDA was injected into the $\mathrm{mfb}$, corresponding to $1.5 \mu \mathrm{g}$ of 6-OHDA. Four other mice served as the sham group : each animal received a unilateral injection of $0.02 \%$ ascorbic acid (vehicle), according to the procedure described above. After the surgery, the skin was sutured and the eight mice were allowed to recover.

\section{Behavioral assessment}

The severity of the dopamine lesion was assessed 20 days after 6-OHDA or vehicle unilateral injections. Mice from the two experimental groups were introduced in a large glass cylinder and spontaneous motor behavior was recorded for $10 \mathrm{~min}$, using a digital camera. The number of spontaneous rotations ipsilateral and contralateral to the injection side were then counted post-hoc, by an experimenter blinded to the experimental treatment.

\section{Tissue preparation}

Forty days following 6-OHDA or vehicle stereotaxic injections, animals were deeply anesthetized with a mixture of ketamine and xylazine $(100 \mathrm{mg} / \mathrm{kg}, 10 \mathrm{mg} / \mathrm{kg}$, i.p.), and perfused transcardially with an initial wash of $0.9 \%$ saline $(50 \mathrm{~mL})$, followed by $2 \%$ acroleine diluted in phosphate buffer $(\mathrm{PB}, 100 \mathrm{~mL})$ and by $4 \%$ paraformaldehyde (PFA; $100 \mathrm{~mL}$, diluted in PB). Brains were dissected out, post-fixed for $1 \mathrm{~h}$ in a $4 \%$ PFA solution and cut with a vibratome (Leica VT1200S) into $50 \mu \mathrm{m}$-thick coronal sections, which were serially collected in sodium phosphate buffer saline (PBS, 0.1M, pH 7.4).

\section{Immunostaining of TH and DAT}


For each mouse, two coronal sections were selected through the striatum at 1.42 and $0.14 \mathrm{~mm}$ relative to the bregma, and one section through the substantia nigra at $-3.10 \mathrm{~mm}$ from the bregma (Franklin and Paxinos 1997). These sections were immunostained for tyrosine hydroxylase (TH) in order to assess to the DA lesion caused by 6-OHDA injection. Briefly, sections were incubated for 30 min into a $0.5 \%$ solution of sodium borohydride $\left(\mathrm{NaBH}_{4}\right)$ diluted in PBS then rinsed thoroughly in PBS. Sections were then preincubated for $1 \mathrm{~h}$ into a blocking solution composed of $0.1 \%$ Triton $\mathrm{X}-100,2 \%$ of normal donkey serum diluted in PBS. They were then incubated overnight (ON) with a polyclonal rabbit antibody against $\mathrm{TH}$ (Catalog \# AB152, Millipore) diluted 1:1000 in the blocking solution. Sections were rinsed in PBS and incubated for $2 \mathrm{~h}$ with an anti-rabbit biotinylated secondary antibody (Catalog \# 711-075-152 58142, Jackson Immunoresearch Laboratories) raised in donkey and diluted 1:1000 in the blocking solution. Sections were rinsed and incubated for $1 \mathrm{~h}$ with the avidin-biotin-peroxidase complex (Catalog \# PK4000, Vector Laboratories). Sections were then rinsed once in PBS and twice in Tris-saline buffer (TBS; $50 \mathrm{mM}$, $\mathrm{pH} 7.4$ ) and incubated for $3 \mathrm{~min}$ in a solution containing $0.05 \%$ of 3,3' diaminobenzidine (Catalog \#D5637, Sigma) and $0.005 \% \mathrm{H}_{2} \mathrm{O}_{2}$ diluted in TBS to reveal the bound peroxidase. Finally, sections were rinsed in TBS to stop the reaction and mounted on gelatine-coated slides, air-dried overnight, dehydrated in alcohol grade series, cleared in toluene and coverslipped with Permount.

To assess quantitatively the DA lesion, two coronal sections per mouse were selected through the striatum (bregma $=0.14 \mathrm{~mm}$ ) and the nucleus accumbens (NAc, bregma $=1.42 \mathrm{~mm}$ ) and doubly stained for $\mathrm{TH}$ and the dopamine membrane transporter (DAT) with infrared immunofluorescence. Sections were first incubated for 30 min with $0.5 \% \mathrm{NaBH}_{4}$, then rinsed thoroughly in PBS. They were then pre-incubated for $1 \mathrm{~h}$ in $0.5 \%$ Triton $\mathrm{X}-100$ in PBS containing $2 \%$ of normal goat serum and normal donkey serum (blocking solution). Sections were incubated $\mathrm{ON}$ in the blocking solution containing the same $\mathrm{TH}$ antibody as above (Catalog \# AB152, Millipore, 1:1000) and a monoclonal antibody against DAT (Catalog \# MAB369, Millipore, 1:1000). Then, sections were rinsed in PBS and incubated for $2 \mathrm{~h}$ in the blocking solution to which a secondary antibody IRDye 680 anti-rabbit (Catalog \# LIC-926-32223, Mandel, 1:1000) raised in donkey and an IRDye 800 anti-rat (Catalog \#LIC-926-32219, Mandel, 1:1000) raised in goat were added. Sections were then rinsed and mounted on gelatine-coated slides, air-dried, and coverslipped with Dako fluorescence mounting medium (Catalog \# S-3023, Mississauga, ON, Canada).

\section{Immunostaining of $C R$}

To assess the regional distribution of $\mathrm{CR}+$ interneurons in the striatum, 6 equally-spaced coronal sections (bregma $1.30 \mathrm{~mm}$ to $-1.70 \mathrm{~mm}$, interval of $600 \mu \mathrm{m}$ ) were randomly selected throughout the entire striatum from the $46-\mathrm{OHDA}$-lesioned mice and the 4 sham-lesioned animals. These sections were singly labeled for the calcium binding protein CR. Briefly, the 6 striatal sections per animal were preincubated for $1 \mathrm{~h}$ in a blocking solution composed of $0.1 \%$ Triton $\mathrm{X}-100$ and $2 \%$ of normal donkey serum diluted in PBS. They were then incubated ON with an antibody against CR (Catalog \# 7699/4, Swant) diluted 1:500 in the blocking solution. Sections were then rinsed in PBS and incubated for $2 \mathrm{~h}$ with a secondary antibody against rabbit coupled to Alexa Fluor 594 and raised in donkey (Catalog \# 711-075-152; Jackson Immunoresearch Laboratories, 1:200). Sections were rinsed in PBS, incubated for 10min with a 100 
$\mathrm{ng} / \mathrm{mL}$ dilution of 4', 6-diamidino-2-phenylindole (DAPI) in PBS, used as counterstaining. Sections were finally rinsed in PBS and mounted on gelatine-coated slides, air-dried, and coverslipped with Dako fluorescence mounting medium (Catalog \# S-3023, Mississauga, ON, Canada).

\section{Double immunostaining of $C R$ and $C B$}

To determine the regional distribution of $\mathrm{CR}+$ interneurons in the shell and core compartments of the NAc, 3 more sections (bregma 1.30, 1.10 and $0.90 \mathrm{~mm}$ ) were selected throughout the NAc from the 4 6-OHDAlesioned mice and the 4 sham-lesioned animals. These sections were doubly stained for CR and calbindin-D-28K (CB). Briefly, the same protocol described above was used, except that normal goat serum was added to the blocking solution as well as a monoclonal primary antibody against CB (Catalog\# C9848, Sigma, 1:500). In addition, a secondary antibody against mouse and coupled to Alexa Fluor 488 and raised in goat was used at a dilution 1:200 (Catalog \#A11001, MolecularProbes).

\section{Data analysis}

Assessment of the dopamine lesion

In each mouse, the dopamine lesion induced by 6-OHDA stereotaxic injections was assessed from sections of the striatum and the NAc stained for TH and DAT using the IRDye 680, and the IRDye 800 respectively, as described above. Sections were scanned using the Odyssey imager (LiCor biotechnology). For each mouse, regions of interest were randomly selected by drawing 6 boxes in the striatum and 6 boxes in the NAc ( 3 in the core and 3 in the shell) of $150 \mu \mathrm{m}^{2}$ on both the intact (left) and lesioned (right) side. Mean TH and DAT immunoreactivity values obtained from the lesioned striatum or NAc, divided by immunoreactivity measured from the intact side x100 was used to report the residual immunoreactivity.

Stereological counting of CR+ cells

In each mouse, the 6 equally-spaced sections selected across the entire striatum ( $600 \mu \mathrm{m}$ interval) were examined with a confocal Laser Scanning Microscope (LSM700, Zeiss) equipped with a camera (AxioCam), a motorized stage ( $\mathrm{X}$ and $\mathrm{Y}$ axes) and a $\mathrm{Z}$-axis indicator (Leica $\mathrm{Z}$ axis control) and controlled by a computer running Stereolnvestigator software. A detailed scanning of the regional distribution of $\mathrm{CR}+$ interneurons throughout the striatum was achieved by dividing the structure into 8 distinct sectors: antero-dorso-lateral ( $A D L)$, antero-dorso-median $(A D M)$, antero-ventro-lateral $(A V L)$, antero-ventro-median $(A V M)$, postero-dorso-lateral (PDL), postero-dorso-median (PDM), postero-ventro-lateral $(\mathrm{PVL})$ and postero-ventro-median (PVM). The contour of the striatum was first outlined on each CR-immunostained coronal section using a $4 \mathrm{X} / 0.10$ objective, according to the stereotaxic atlas of Franklin and Paxinos (1997). A vertical line parallel to the midline and passing by the center of the striatum was first traced, dividing the structure into medial and lateral sectors (Fig. 1A). A horizontal line, perpendicular to and centered on the vertical line was added to delineate four sectors on each brain section. The anteroposterior axis was then divided in two by considering the first 3 coronal sections as representative of anterior (pre-commissural) sectors and the last 3 of posterior (post-commissural) sectors. The 3 
sections ( $200 \mu \mathrm{m}$ interval) taken trough the NAc of each mouse and doubly stained for CR and CB were also analyzed stereologically, the CB immunostaining being used to delineate the core from the shell. The number of doubly stained cells encountered was counted.

The sampling process leading to the estimation of the total number of $\mathrm{CR}+$ interneurons in each of the striatal sectors and in the core and the shell of the NAc began by using a grid formed by $157 \times 157 \mu \mathrm{m}$ squares placed over each section. At each intersection of the grid that fell into the sector, a counting frame of the same size was drawn and examined with a 40X/1.4 objective leading to the examination of the entire area of each sector (Fig. 1B). On each selected section, a mean number of $48.9+4.7$ sampling sites in each striatal sector, $42.1+4.2$ in the shell and $39.4+4.0$ in the core, were examined. Neurons that fell inside the counting frame and did not contact the exclusion lines were counted whenever their nucleus came into focus within a $12 \mu \mathrm{m}$-thick optical disector centered in the section (Fig. 1C). An average of $202 \pm 29 \mathrm{CR}+$ cells were counted in each striatum ipsilateral to the sham or 6-OHDA lesion whereas $181 \pm 24$ were counted in each striatum contralateral to the lesion, yielding coefficients of error (Gundersen, $m=1$ and 2nd Schmitz-Hof) ranging from 0.06 to 0.12 and from 0.06 to 0.14 , respectively. In the NAc, an average of $103 \pm 21 \mathrm{CR}$ interneurons were counted ipsilateral to the sham or 6-OHDA lesion, while $99 \pm 19$ were counted contralateral to the lesion, yielding coefficients of error (Gundersen, $m=1$ and 2nd Schmitz-Hof) between 0.08 and 0.23 , and between 0.07 and 0.22 , respectively. These coefficients of error are used to assess the precision of the estimation by taking into account the shape of the region of interest, the distribution of neurons within this region and the sampling criteria, predicting the accuracy of stereological procedure (Gundersen et al. 1999; Schmitz and Hof 2000). For each striatal and NAc region, the density of $\mathrm{CR}+$ cells was expressed in number of $\mathrm{CR}+$ neurons per $\mathrm{mm}^{3}$ of tissue, using the total number estimated by the optical disector and the volume of each sector, as estimated by Cavalieri's method (García-Fiñana et al. 2003). The proportion of CR+ cells expressing CB was determined from doubly stained sections (as described above) by using two different stereological markers for $\mathrm{CR}+\mathrm{CB}$ cells and for $\mathrm{CR}+/ \mathrm{CB}+$ cells.

\section{Statistical analysis}

Differences in the density of CR cells among the striatal regions (anterior vs posterior, dorsal vs ventral and medial vs lateral) as well as between treatment (6-OHDA vs sham-lesioned animals) were assessed by two-way analysis of variance (two-way ANOVA). The dependent variables considered were the regions and the treatments. The Tukey multiple comparison test was applied post-hoc. Differences in spontaneous motor behavior, TH and DAT immunoreactivity between sham and 6-OHDA-lesioned mice were assessed using the Mann-Whitney nonparametric statistical test. Differences were considered statistically significant at $P<0.05\left(^{*}\right)$. Statistical analyses were performed by using sample sizes of 4 animals per group and the GraphPad Prism software (v.9.0, San Diego, CA, USA). Mean and standard error of the mean are used throughout the text as central tendency and dispersion measure.

\section{Results}




\section{The 6-OHDA-lesioned mice exhibit a preferential rotational behavior ipsilateral to the lesioned side and a marked reduction of TH and DAT immunoreactivity in striatum and NAC}

Quantification of mouse spontaneous motor behavior following surgery revealed a marked preferential rotational behavior towards the 6-OHDA-lesioned side (right). In 6-OHDA-lesioned mice, we observed that $97 \pm 2 \%$ of spontaneous rotations were directed towards the lesioned-side, compared to a normal value of $54 \pm 12 \%$ for sham-lesioned animals. Our quantitative immunohistochemical analysis revealed a significant decrease of TH immunoreactivity in the 6-OHDA-lesioned striatum, compared to the intact counterpart and to sham-lesioned animals (Fig. 2). The 6-OHDA group showed a TH residual content of only $9 \pm 1 \%$ in the lesioned striatum compared to $105 \pm 4 \%$ for the sham group. In the core and shell compartments of the NAc, the 6-OHDA group of mice presented a similar TH residual content of $20 \pm 11 \%$ and $25 \pm 14 \%$, that were both significantly lower than what was observed in sham animals $(110 \pm 13 \%$ and $102 \pm 3 \%$ ). The efficacy of the 6-OHDA lesion of the dopamine striatal and NAc afferent axons was also supported by a significant decrease of DAT immunoreactivity, the striatum of 6-OHDA-lesioned mice showing a DAT residual content of only $7 \pm 2 \%$ compared to $103 \pm 10 \%$ for the sham group. Similarly, the NAc of 6-OHDA-lesioned animals was characterized by a DAT residual content of $14 \pm 6 \%$ and $21 \pm 9 \%$ in the core and the shell, compared to $110 \pm 18 \%$ and $96 \pm 4 \%$ for the sham-lesioned experimental group. As expected, no significant differences were observed in the striatum and the NAc between the intact side of 6-OHDA and the sham-lesioned or intact side of sham animals, for both TH and DAT staining.

\section{In the mouse striatum, two types of CR+ interneurons are observed with opposite dorsoventral distribution, whereas only one type is present in the NAC}

Based on their soma size and somatodendritic morphological features, we detected two types of striatal $\mathrm{CR}+$ interneurons in the murine specimens used in the present study.

Neurons of the first type were intensely-stained for CR and endowed with a small-sized (9-12 $\mu \mathrm{m})$ cell body displaying slightly varicose and beaded processes (Fig. 3A, C). The vast majority of them were unipolar, but a small number of bipolar cells were also observed. Some of the small CR+ interneurons formed clusters along the subventricular zone and the subcallosal streak, especially in the anterior part of the striatum. Interestingly, this type of $\mathrm{CR}+$ interneurons was completely absent from the NAc. In the striatum itself, the small aspiny $\mathrm{CR}+$ interneurons displayed an anteroposterior and dorsoventral decreasing gradient. Indeed, the quantification of the small-sized $\mathrm{CR}+$ interneurons in the sham-lesioned striatum showed that they prevailed in the pre-commissural striatal sectors $\left(222 \pm 32 \mathrm{cells} / \mathrm{mm}^{3}\right)$ and are less abundant in the post-commissural striatum $\left(49 \pm 14\right.$ cell $\left./ \mathrm{mm}^{3}, \mathrm{Fig} .4 \mathrm{~A}\right)$. The density of these interneurons was also significantly higher in the dorsal half of the sham-lesioned striatum $(252 \pm 41$ cells $\left./ \mathrm{mm}^{3}\right)$ compared to its ventral counterpart $\left(65 \pm 23 \mathrm{cells} / \mathrm{mm}^{3}\right)$. A similar density was observed in the medial $\left(159 \pm 31 \mathrm{cells} / \mathrm{mm}^{3}\right)$ and lateral $\left(169 \pm 28 \mathrm{cells} / \mathrm{mm}^{3}\right)$ striatal sectors. Such neurons are totally absent from the NAc. 
Neurons of the second type are weakly labeled for CR and are endowed with a medium-sized (15-20 $\mu \mathrm{m})$ cell body displaying smooth aspiny dendrites (Fig. 3B, D). The density of medium-sized CR+ interneurons in the entire striatum was twice as high than that of the small-sized interneurons $\left(370 \pm 41 \mathrm{cells} / \mathrm{mm}^{3} \mathrm{vs}\right.$ $164 \pm 22$ ). Our stereological quantification in the sham-lesioned striatum indicated that medium-sized $\mathrm{CR}+$ interneurons are distributed according to a dorsoventral increasing gradient (Fig. 4B). In contrast to the small-sized $\mathrm{CR}+$ interneurons, medium-sized $\mathrm{CR}+$ cells prevailed in the ventral half of the striatum (466 \pm 54 cells $/ \mathrm{mm}^{3}$ vs $276 \pm 43$ for the dorsal counterpart), whereas they appeared rather homogeneously distributed along the anteroposterior (396 \pm 46 cells $/ \mathrm{mm}^{3}$ vs $312 \pm 68$ ) and the mediolateral (325 \pm 43 cells $/ \mathrm{mm}^{3}$ vs $\left.423 \pm 57\right)$ axes.

In contrast to the small-sized CR+ interneurons observed exclusively in the striatum, the medium-sized interneurons were also found in the NAc, where they were significantly more numerous than in the striatum $\left(1,237 \pm 335\right.$ cells $/ \mathrm{mm}^{3}$ vs $\left.370 \pm 41\right)$. Morphologically, the medium-sized CR+ interneurons observed in the NAc were similar to those found in the striatum (Fig. 5).

The shell and core compartments of the NAc could easily be delineated from CB-immunostained sections, the shell being characterized by a low level of CB immunoreactivity (Fig. 5A). The CR immunoreactive neuropil was denser in the shell compartment than in the core, particularly in its dorsomedial portion. The density of medium-sized $\mathrm{CR}+$ interneurons was similar in the shell and core compartments of sham-lesioned NAc $\left(1,220 \pm 345\right.$ cells $/ \mathrm{mm}^{3}$ vs 1,340 \pm 357 , Fig. 4B). It should be noted that $26 \pm 3 \%$ of the $\mathrm{CR}+$ interneurons observed in the shell were also immunoreactive for CB compared to only $7 \pm 4 \%$ in the core (Fig. 5B, C).

\section{The density of the small-sized CR+ interneurons in the striatum is unaffected by 6-OHDA lesion}

The small-sized CR+ interneurons had similar morphological features and CR immunoreactivity in the 6OHDA and the sham-lesioned striatum (Fig. 3A, C). They were also regionally distributed according to the same anteroposterior (248 \pm 71 cells $/ \mathrm{mm}^{3}$ vs $\left.38 \pm 16, P=0.029\right)$ and dorsoventral $\left(308 \pm 80 \mathrm{cells} / \mathrm{mm}^{3}\right.$ vs $31 \pm 12, P=0.029$ ) decreasing gradient (Fig. 4A). Overall, we found a similar density of the small-sized $\mathrm{CR}+$ interneurons in the sham-lesioned striatum $\left(164 \pm 22\right.$ cells $\left./ \mathrm{mm}^{3}\right)$ and the 6-OHDA-lesioned striatum $\left(174 \pm 46\right.$ cells $\left./ \mathrm{mm}^{3}\right)$, indicating that dopamine striatal deafferentation had no significant effect on this specific subtype of $\mathrm{CR}+$ interneurons. This finding was supported by the absence of statistical differences in the density of the small-sized CR+ interneurons between the intact $\left(177 \pm 44 \mathrm{cells} / \mathrm{mm}^{3}\right)$ and the 6-OHDA-lesioned striatum $\left(174 \pm 46 \mathrm{cells} / \mathrm{mm}^{3}\right)$ of 6-OHDA mice. No significant differences were observed between the intact $\left(120 \pm 10\right.$ cells $\left./ \mathrm{mm}^{3}\right)$ and the sham-lesioned striatum $\left(164 \pm 22 \mathrm{cells} / \mathrm{mm}^{3}\right)$, nor between the intact striatum of the sham group (120 \pm 10 cells $\left./ \mathrm{mm}^{3}\right)$ and the intact striatum of 6 OHDA mice (177 \pm 44 cells $/ \mathrm{mm}^{3}$, Fig. 4C).

In 6-OHDA-lesioned mice, the density of the medium-CR+ interneurons is significantly decreased in the striatum but unaltered in the NAC 
The medium-sized CR+ interneurons displayed similar morphological features in the 6-OHDA and the sham-lesioned striatum, with no signs of degeneration in the 6-OHDA-lesioned animals. In 6-OHDAlesioned mice, they also displayed a similar level of $\mathrm{CR}$ immunoreactivity and regional distribution than in controls, their density being higher in the ventral striatal sectors $\left(233 \pm 17\right.$ cells $\left./ \mathrm{mm}^{3}\right)$ than in dorsal counterparts ( $82 \pm 15$ cells $/ \mathrm{mm}^{3}$, Fig. $4 \mathrm{~B}$ ). Comparison of the density of medium-sized CR+ interneurons in the $6-\mathrm{OHDA}$ lesioned striatum $\left(158 \pm 15 \mathrm{cell} / \mathrm{s} / \mathrm{mm}^{3}\right)$ revealed a significant decrease compared to what was observed in the sham-lesioned striatum $\left(370 \pm 41 \mathrm{cells} / \mathrm{mm}^{3}\right)$. Although the decrease appeared rather homogeneous throughout the whole striatum (40-72\% decrease), we found the highest decrease in the dorsal (70\%) and lateral (72\%) striatal sectors and the lowest in the ventral (50\%) and medial (40\%) counterparts. Interestingly, the density of the medium-sized CR+ cells was also found to be almost similarly decreased in the intact striatum of 6-OHDA mice (143 \pm 53 cells $\left./ \mathrm{mm}^{3}\right)$, when compared to either the sham-lesioned $\left(370 \pm 41\right.$ cells $\left./ \mathrm{mm}^{3}\right)$ or the intact striatum $\left(316 \pm 29\right.$ cells $\left./ \mathrm{mm}^{3}\right)$ of sham animals (Fig. 4D). Although non statistically significant, these results suggest an indirect consequence of the 6OHDA lesion on the density of the medium-sized CR+ striatal cells of the striatum.

In the NAc, the density of the medium-sized CR+ neurons was similar between $6-\mathrm{OHDA}(1,074 \pm 204$ cells $\left./ \mathrm{mm}^{3}\right)$ and sham-lesioned mice $(1,237 \pm 335)$, with no significant change in their regional distribution between the core $\left(1,146 \pm 215\right.$ cells $\left./ \mathrm{mm}^{3}\right)$ and the shell $(1,104 \pm 227)$, when compared to sham animals (1,220 \pm 345 and 1,340 \pm 357 , Fig. 4B). As expected, similar densities were observed between the 6 -OHDA-lesiond NAc $\left(1,074 \pm 204\right.$ cells $\left./ \mathrm{mm}^{3}\right)$ and intact NAc $(1,193 \pm 169)$ of 6 -OHDA mice, as well as between sham-lesioned $\left(1,237 \pm 335 \mathrm{cells} / \mathrm{mm}^{3}\right)$ and intact NAc $\left(1,258 \pm 167 \mathrm{cells} / \mathrm{mm}^{3}\right)$ of sham animals. No changes in the proportion of the $\mathrm{CR}+\mathrm{CB}+$ doubly-stained neurons were noted between $6-\mathrm{OHDA}$ and sham-lesioned NAc, either in the core ( $8 \pm 4 \%$ vs $7 \pm 4$ ) nor the shell ( $26 \pm 3 \%$ vs $26 \pm 3$ ).

\section{Discussion}

The present study has provided the first detailed quantitative description of changes that affect CR+ striatal interneurons in a mouse model of Parkinson's disease. Two morphologically distinct types of CR+ aspiny striatal interneurons were detected in mice: a) small, unipolar cells that stained intensely for $\mathrm{CR}$, displayed beaded dendrites and were distributed according to a dorsoventral decreasing gradient; $b$ ) medium-sized bipolar neurons that stain weakly for $\mathrm{CR}$, displayed smooth dendrites and were scattered according to a dorsoventral increasing gradient (see also Petryszyn et al. 2014; Garas et al. 2018). This study also provides a detailed description of the distribution of $\mathrm{CR}+$ cells in the NAc of mice. In contrast to the striatum, where both small and medium-sized $\mathrm{CR}+$ interneurons occurred, the mouse NAc contains only medium-sized $\mathrm{CR}+$ cells that are rather evenly distributed between its core and shell compartments. The medium-sized $\mathrm{CR}+$ cells in NAc were morphologically similar to the $\mathrm{CR}+$ neurons of the same size that occurred in the striatum. These results are in accordance with previous observations made in the rat (Hussain et al. 1996) and mouse (Trouche et al. 2019) NAc. 
Previous investigations have revealed that GABAergic cells expressing CR form the most abundant class of interneurons in the striatum of primates (Cicchetti et al. 2000; Wu and Parent 2000) and there is evidence that newborn $\mathrm{CR}+$ interneurons continue to be added to the adult striatum in both normal (Ernst et al. 2014) and pathological conditions (Wei et al. 2011). In most species investigated thus far, the striatum was described as containing either small-, medium- or large-sized CR+ interneurons or a combination thereof: rats (Mura et al. 2000; Rymar et al. 2004; Wu and Parent 2000; Garas et al. 2018), human (Cicchetti et al. 2000; Parent et al. 1995; Petryszyn et al. 2014) and non-human primates (Petryszyn et al. 2014; Petryszyn et al. 2016; Wu and Parent 2000). The primate striatum harbours a unique population of giant $\mathrm{CR}+$ interneurons, which express choline acetyltransferase (ChAT), a faithful marker of cholinergic neurons (Bernacer et al. 2012; Kataoka et al. 2010a; Petryszyn et al. 2014; Petryszyn et al. 2016). These large-sized $C R+/ C h A T+$ interneurons are significantly decreased in number in the striatum of parkinsonian monkeys, a change that was shown to reflect a higher level of CR expression by ChAT+ interneurons rather than an increase in their absolute number (Petryszyn et al. 2016).

Such giant CR+ interneurons that express ChAT do not occur in the striatum of mice. The latter contains a significant number of medium-sized $\mathrm{CR}+$ interneurons, which are morphologically and neurochemically similar to striatal $\mathrm{CR}+$ interneurons of the same size detected in other species, and a smaller number of small-sized, unipolar CR+ cells that prevail in the anterodorsal sector of the striatum, near the subventricular zone, an area that retains its neurogenic capacity throughout adult life (Ming and Song 2011). The immature appearance of these small CR+ interneurons and their presence near the neurogenic zone of the striatum suggest that they might be issued from postnatal neurogenesis, as it appears to be the case in normal adult rats (Dayer et al. 2005; Garas et al. 2018), rabbits (Luzzati et al. 2006) and human (Ernst et al. 2014). Evidence for small CR+ neurons generated during early postnatal development has also been obtained in mice (Revishchin et al. 2010a; Revishchin et al. 2010b). These immature looking cells were described as having a perikaryon and processes coated with polymorphous spines; they thus differ markedly from the typical GABAergic CR+ aspiny striatal interneurons as well as from the small-sized CR+ cells described in the present study.

In addition to the typical small, medium and large-sized striatal $\mathrm{CR}+$ interneurons know to be present in rats (Rymar et al. 2004; Wu and Parent 2000; Garas et al. 2018), two additional types of CR+ cells were described following a study of rats with a 6-OHDA-lesion of the nigrostriatal pathway (Mura et al. 2000). In that study, neurons of the first type were detected in both dopamine-depleted and intact striata and consisted of small unipolar CR+ cells endowed with an irregular dendritic tree that branches very near to the cell body in a bush-like pattern. Neurons of the second type, present only in the 6-OHDA-lesioned striatum, were less numerous and composed of uni- or bipolar $\mathrm{CR}+$ cells with dendrites displaying tiny and widely interspaced spine-like structures. The morphological features of these small CR+ cells in the rat striatum do not match with those observed in the present study in mice. Furthermore, in that single study, an overall increase of $\mathrm{CR}+$ cells was noted in dopamine-lesioned striatum 3 weeks following 6OHDA injection, but this augmentation tended to normalized at 6,10 , and 18 weeks post-lesion (Mura et al. 2000). Whether this increase could solely be explained by a postnatal production of these two new types of CR+ cells or by a transient increase in the expression of CR is unclear. In this regard, it should be 
reminded that the expression of CR appears to be transitory in many neuronal types and could vary according to the maturation state of the neurons (Schwaller 2014).

The present investigation of the dopamine-depleted striatum in mice has revealed that the two types of striatal CR+ cells detected previously in normal animals (Petryszyn et al. 2014) occur in the 6-OHDAlesioned striatum and its sham counterpart, their regional distribution, morphological characteristics and neurochemical makeups being totally unaltered by dopamine depletion. However, the density of the medium $\mathrm{CR}+$ cells was reduced by half in the dopamine-lesioned striatum, while that of the small-sized $\mathrm{CR}+$ interneurons remained unaffected. Such a 6-OHDA-induced decrease in the number of medium-sized $\mathrm{CR}+$ striatal cells with no alteration of the small $\mathrm{CR}+$ cells observed here in mice is at variance with the transient increase in the number of striatal $\mathrm{CR}+$ cells reported in rats under the same pathological condition (Mura et al. 2000). Such a discrepancy could be due either to species differences or variations in experimental designs. It should be noted that the present observations were made almost 6 weeks following 6-OHDA lesion, a period during which the increase noted in rats was shown to be back to normal (Mura et al. 2000). It is thus tempting to hypothesize that the increase in the number of CR+ cells noted 3 weeks following 6-OHDA injection in rats is the result of a higher level of CR expression, as part of an early compensatory mechanism designed to cope with increased intracellular calcium level that might occur following altered glutamatergic corticostriatal transmission that is believed to characterize Parkinson's disease (Calabresi et al. 1996; Cepeda et al. 1998). In regard to the preservation of the small striatal CR+ cells observed in the present study, it is worth noting that these neurons abound in the anterior sector of the striatum, which is principally innervated by cortices of the associative type. Such a specific topographical and connectional relationship suggests that the small $\mathrm{CR}+$ interneurons are chiefly involved in the integrative role of the striatum, whereas the medium-sized CR+ interneurons, which are affected by dopamine depletion, are principally concerned with the sensorimotor or limbic function of the striatum, which are dealt with in more posterior and ventral aspects of the structure. The topographical distribution and high level of $\mathrm{CR}$ expression displayed by the small-sized $\mathrm{CR}+$ striatal cells might render them less vulnerable than the medium-sized $\mathrm{CR}+$ interneurons to increased calcium levels derived from enhanced striatal excitatory input arising from the cerebral cortex (Mitchell et al. 1994; Blandini et al. 1996; Calabresi et al. 1996; Meshul et al. 1999).

The decreased in the density of the medium-sized CR+ interneurons reported here in the striatum of 6OHDA-lesioned mice is congruent with the results of another study in 6-OHDA rats, in which a significant decrease of $\mathrm{CR}+$ interneurons was observed in the ipsilateral striatum, 5 weeks following unilateral 6OHDA injection (Ma et al. 2014). In the latter study, however, the existence of various morphological subtypes of $\mathrm{CR}+$ cells has not been taken into account in the quantitative analysis so that it is not possible to know if some types of $\mathrm{CR}+$ striatal interneurons might have been spared in the 6-OHDAlesioned rats, as it is the case in 6-OHDA-lesioned mice.

Weather the decrease of the medium-sized CR+ interneurons reported in the present study is caused by neuronal death or result from a decreased in CR expression following dopamine striatal denervation is unknown. However, it should be noted that the same level of CR immunoreactivity was observed in the 
sham and 6-OHDA-lesioned striatum and that no morphological signs of neuronal degeneration were observed for these medium CR+ striatal cells in the 6-OHDA-lesioned striatum. Through its capacity of maintaining intracellular calcium homeostasis, CR is believed confer to neurons a certain protection against neurodegenerative processes, particularly glutamatergic excitotoxicity, which is considered a major pathogenic component of Parkinson's disease (Choi 2005). This could explain why the mediumsized $\mathrm{CR}+$ were selectively affected in the 6-OHDA-lesioned striatum, being less immunoreactive for $\mathrm{CR}$ than the small-sized $\mathrm{CR}+$ cells for which the density appears unchanged.

Also of interest is the fact that the intact striatum of 6-OHDA-lesioned mice also showed a trend towards decreased density of $\mathrm{CR}+$ medium interneurons, a tendency not observed in the sham-lesioned mice. Although not statistically significant, such a finding suggests an indirect effect of the dopamine lesion on striatal $\mathrm{CR}+$ interneurons. A possible influence of dopamine on $\mathrm{CR}+$ striatal neurons has been alluded to previously (Kawaguchi et al. 1995), but the mechanism whereby such a putative dopaminergic action might be exerted has remained elusive. Immunohistochemical studies in rats have shown that CR+ interneurons express a low level of the dopaminergic $D_{5}$ receptors (Rivera et al. 2002), but such neurons appear to be completely devoid of the $D_{1}$ and $D_{2}$ receptors (Petryszyn et al. 2014). Thus, dopamine is likely to exert its influence upon $\mathrm{CR}+$ striatal interneurons indirectly, probably by modulating the glutamatergic excitatory striatal projections of cortical or thalamic origin. The fact that the most significant decrease of the medium-sized $\mathrm{CR}+$ cells was observed in the dorsolateral sectors of 6-OHDAlesioned striatum and that no changes were observed in the NAc indicates that the medium-sized striatal interneurons expressing low level of $\mathrm{CR}$ and located in the sensorimotor striatal territory might be particularly vulnerable to an increase in intracellular calcium. This possibility is further strengthened by data indicating that perturbations of glutamatergic cortiostriatal transmission induced by striatal dopamine-depletion are particularly conspicuous in the sensorimotor striatal territory (Meshul et al. 1999; Blandini et al. 1996).

The intensity of the immunostaining for TH and DAT in the intact striatum of 6-OHDA-lesioned striatum was similar to that in sham animals. Hence, despite the fact that $5-10 \%$ of nigrostriatal axons have been reported to cross the midline in normal condition (Fass and Butcher 1981), it's is difficult to attribute the bilateral decrease of medium $\mathrm{CR}+$ striatal cells to a lower dopamine concentration in the intact striatum of 6-OHDA-lesioned striatum compared to sham animals. Instead, the involvement of the corticostriatal projections could be a more likely explanation. Corticostriatal neurons are able to reach their target by either an ipsilateral, contralateral or bilateral projection (Hooks et al. 2018; Kiritani et al. 2012; Parent and Parent 2006). Hence, a bilaterally altered corticostriatal transmission could indeed explain, at least in part, the bilateral reduction of $\mathrm{CR}+$ medium cells in 6-OHDA-lesioned mice. It is worth noting that various bilateral effects have often been reported following unilateral 6-OHDA lesion (Avila-Costa et al. 2005; Jedrzejewska et al. 1990; Nikolaus et al. 2003), including a transient increase in the number of striatal $\mathrm{CR}+$ neurons following unilateral 6-OHDA-lesion in rats (Mura et al. 2000). However, a potential systemic effect of the 6-OHDA injection cannot be ruled out, particularly because increased level of pro- 
inflammatory cytokines and reduced concentrations of neurotrophic factors have previously been reported in the 6-OHDA-lesioned mice (Antunes et al. 2020).

\section{Declarations}

Funding: This study was supported by research grants from the Canadian Institutes of Health Research (CIHR 153068 to M.P.) and the Natural Sciences and Engineering Research Council of Canada (NSERC 06264 and 522690 to M.P.).

Conflicts of interest/Competing interests: The authors have no conflict of interest to declare.

Ethics approval: All protocols were approved by the Institutional Animal Care and Use Committee (Comité de Protection des Animaux de l'Université Laval, \# 2019-287/VRR-18-107) and all procedures involving animals and their care were made in accordance with the Canadian Council on Animal Care's Guide to the Care and Use of Experimental Animals (Ed2).

Consent to participate: Not applicable

Consent for publication: All authors have read and approved the final version of the manuscript.

Availability of data and material: Not applicable

Code availability: Not applicable

Authors' contributions: SP was in charge of running experiments. SP and LS were in charge of data and statistical analyses. DG provided guidance for stereology. MP designed experiments and wrote the manuscript. AP revised the manuscript.

\section{References}

1. Antunes MS, Cattelan Souza L, Ladd FVL, Ladd A, Moreira AL, Bortolotto VC, Silva MRP, Araujo SM, Prigol M, Nogueira CW, Boeira SP (2020) Hesperidin Ameliorates Anxiety-Depressive-Like Behavior in 6-OHDA Model of Parkinson's Disease by Regulating Striatal Cytokine and Neurotrophic Factors Levels and Dopaminergic Innervation Loss in the Striatum of Mice. Mol Neurobiol 57 (7):3027-3041. doi:10.1007/s12035-020-01940-3

2. Avila-Costa MR, Colín-Barenque L, Aley-Medina P, Valdez AL, Librado JL, Martinez EF, Fortoul TI (2005) Bilateral increase of perforated synapses after unilateral dopamine depletion. The International journal of neuroscience 115 (1):79-86

3. Bernacer J, Prensa L, Gimenez-Amaya JM (2012) Distribution of GABAergic interneurons and dopaminergic cells in the functional territories of the human striatum. PloS one 7 (1):e30504. doi:10.1371/journal.pone.0030504 
4. Blandini F, Porter RH, Greenamyre JT (1996) Glutamate and Parkinson's disease. Mol Neurobiol 12 (1):73-94. doi:10.1007/BF02740748

5. Calabresi P, Pisani A, Mercuri NB, Bernardi G (1996) The corticostriatal projection: from synaptic plasticity to dysfunctions of the basal ganglia. Trends Neurosci 19 (1):19-24. doi:10.1016/01662236(96)81862-5

6. Cepeda C, Colwell CS, Itri JN, Gruen E, Levine MS (1998) Dopaminergic modulation of early signs of excitotoxicity in visualized rat neostriatal neurons. The European journal of neuroscience 10 (11):3491-3497. doi:10.1046/j.1460-9568.1998.00357.x

7. Choi DW (2005) Neurodegeneration: cellular defences destroyed. Nature 433 (7027):696-698. doi:10.1038/433696a

8. Cicchetti F, Prensa L, Wu Y, Parent A (2000) Chemical anatomy of striatal interneurons in normal individuals and in patients with Huntington's disease. Brain Res Brain Res Rev 34 (1-2):80-101. doi:10.1016/s0165-0173(00)00039-4

9. Dayer AG, Cleaver KM, Abouantoun T, Cameron HA (2005) New GABAergic interneurons in the adult neocortex and striatum are generated from different precursors. J Cell Biol 168 (3):415-427. doi: $10.1083 /$ jcb. 200407053

10. Ding Y, Won L, Britt JP, Lim SA, McGehee DS, Kang UJ (2011) Enhanced striatal cholinergic neuronal activity mediates L-DOPA-induced dyskinesia in parkinsonian mice. Proc Natl Acad Sci U S A 108 (2):840-845. doi:10.1073/pnas.1006511108

11. Ernst A, Alkass K, Bernard S, Salehpour M, Perl S, Tisdale J, Possnert G, Druid H, Frisén J (2014) Neurogenesis in the striatum of the adult human brain. Cell 156:1072-1083. doi:10.1016/j.cell.2014.01.044

12. Fass B, Butcher LL (1981) Evidence for a crossed nigrostriatal pathway in rats. Neuroscience letters 22 (2):109-113

13. Fieblinger T, Graves SM, Sebel LE, Alcacer C, Plotkin JL, Gertler TS, Chan CS, Heiman M, Greengard P, Cenci MA, Surmeier DJ (2014) Cell type-specific plasticity of striatal projection neurons in parkinsonism and L-DOPA-induced dyskinesia. Nat Commun 5:5316. doi:10.1038/ncomms6316

14. Figueredo-Cardenas G, Harris CL, Anderson KD, Reiner A (1998) Relative resistance of striatal neurons containing calbindin or parvalbumin to quinolinic acid-mediated excitotoxicity compared to other striatal neuron types. Exp Neurol 149 (2):356-372. doi:10.1006/exnr.1997.6724

15. Franklin KBJ, Paxinos G (1997) The mouse brain in stereotaxic coordinates. Academic Press, San Diego

16. Gagnon D, Petryszyn S, Sanchez MG, Bories C, Beaulieu JM, De Koninck Y, Parent A, Parent M (2017) Striatal Neurons Expressing D1 and D2 Receptors are Morphologically Distinct and Differently Affected by Dopamine Denervation in Mice. Sci Rep 7:41432. doi:10.1038/srep41432

17. Garas FN, Kormann E, Shah RS, Vinciati F, Smith Y, Magill PJ, Sharott A (2018) Structural and molecular heterogeneity of calretinin-expressing interneurons in the rodent and primate striatum. $J$ Comp Neurol 526 (5):877-898. doi:10.1002/cne.24373 
18. García-Fiñana M, Cruz-Orive LM, Mackay CE, Pakkenberg B, Roberts N (2003) Comparison of MR imaging against physical sectioning to estimate the volume of human cerebral compartments. Neuroimage 18 (2):505-516

19. Gerfen C, Bolam J (2010) Handbook of Basal Ganglia Structure and Function, Chapter 20, The neuroanatomical organization of the basal ganglia. Academic Press

20. German DC, Manaye KF, Sonsalla PK, Brooks BA (1992) Midbrain dopaminergic cell loss in Parkinson's disease and MPTP-induced parkinsonism: sparing of calbindin-D28k-containing cells. Ann N Y Acad Sci 648:42-62. doi:10.1111/j.1749-6632.1992.tb24523.x

21. Gomez G, Escande MV, Suarez LM, Rela L, Belforte JE, Moratalla R, Murer MG, Gershanik OS, Taravini IRE (2019) Changes in Dendritic Spine Density and Inhibitory Perisomatic Connectivity onto Medium Spiny Neurons in L-Dopa-Induced Dyskinesia. Mol Neurobiol 56 (9):6261-6275. doi:10.1007/s12035019-1515-4

22. Graveland GA, DiFiglia M (1985) The frequency and distribution of medium-sized neurons with indented nuclei in the primate and rodent neostriatum. Brain Res 327 (1-2):307-311

23. Gundersen HJ, Jensen EB, Kieu K, Nielsen J (1999) The efficiency of systematic sampling in stereology-reconsidered. J Microsc 193 (Pt 3):199-211. doi:10.1046/j.1365-2818.1999.00457.x

24. Hooks BM, Papale AE, Paletzki RF, Feroze MW, Eastwood BS, Couey JJ, Winnubst J, Chandrashekar J, Gerfen CR (2018) Topographic precision in sensory and motor corticostriatal projections varies across cell type and cortical area. Nat Commun 9 (1):3549. doi:10.1038/s41467-018-05780-7

25. Huot $P$, Levesque $M$, Parent A (2007) The fate of striatal dopaminergic neurons in Parkinson's disease and Huntington's chorea. Brain 130 (Pt 1):222-232. doi:10.1093/brain/awl332

26. Hussain Z, Johnson LR, Totterdell S (1996) A light and electron microscopic study of NADPHdiaphorase-, calretinin- and parvalbumin-containing neurons in the rat nucleus accumbens. Journal of chemical neuroanatomy 10 (1):19-39

27. Inoue KI, Miyachi S, Nishi K, Okado H, Nagai Y, Minamimoto T, Nambu A, Takada M (2019) Recruitment of calbindin into nigral dopamine neurons protects against MPTP-Induced parkinsonism. Movement disorders : official journal of the Movement Disorder Society 34 (2):200209. doi: $10.1002 / \mathrm{mds} .107$

28. Jedrzejewska A, Wierzba-Bobrowicz T, Olejniczak P, Poszwińska Z, Dymecki J (1990) Ultrastructure and immunocytochemistry of left and right nigrostriatal system after lesion of right side of substantia nigra of rat. Advances in neurology 53:41-49

29. Kataoka Y, Kalanithi PS, Grantz H, Schwartz ML, Saper C, Leckman JF, Vaccarino FM (2010a) Decreased number of parvalbumin and cholinergic interneurons in the striatum of individuals with Tourette syndrome. J Comp Neurol 518 (3):277-291. doi:10.1002/cne.22206

30. Kataoka Y, Kalanithi PS, Grantz H, Schwartz ML, Saper C, Leckman JF, Vaccarino FM (2010b) Decreased number of parvalbumin and cholinergic interneurons in the striatum of individuals with Tourette syndrome. J Comp Neurol 518 (3):277-291. doi:10.1002/cne.22206 
31. Kawaguchi Y, Wilson CJ, Augood SJ, Emson PC (1995) Striatal interneurones: chemical, physiological and morphological characterization. Trends Neurosci 18 (12):527-535

32. Kiritani T, Wickersham IR, Seung HS, Shepherd GM (2012) Hierarchical connectivity and connectionspecific dynamics in the corticospinal-corticostriatal microcircuit in mouse motor cortex. J Neurosci 32 (14):4992-5001. doi:10.1523/JNEUROSCI.4759-11.2012

33. Lee J, Park K, Lee S, Whang K, Kang M, Park C, Huh Y (2002) Differential changes of calcium binding proteins in the rat striatum after kainic acid-induced seizure. Neuroscience letters 333 (2):87-90. doi:10.1016/s0304-3940(02)00987-4

34. Luzzati F, De Marchis S, Fasolo A, Peretto P (2006) Neurogenesis in the caudate nucleus of the adult rabbit. J Neurosci 26 (2):609-621. doi:10.1523/JNEUROSCI.4371-05.2006

35. Ma Y, Zhan M, Ouyang L, Li Y, Chen S, Wu J, Chen J, Luo C, Lei W (2014) The effects of unilateral 6OHDA lesion in medial forebrain bundle on the motor, cognitive dysfunctions and vulnerability of different striatal interneuron types in rats. Behav Brain Res 266:37-45. doi:10.1016/j.bbr.2014.02.039

36. Meshul CK, Emre N, Nakamura CM, Allen C, Donohue MK, Buckman JF (1999) Time-dependent changes in striatal glutamate synapses following a 6-hydroxydopamine lesion. Neuroscience 88 (1):1-16. doi:10.1016/s0306-4522(98)00189-4

37. Ming GL, Song H (2011) Adult neurogenesis in the mammalian brain: significant answers and significant questions. Neuron 70 (4):687-702. doi:10.1016/j.neuron.2011.05.001

38. Mitchell IJ, Lawson S, Moser B, Laidlaw SM, Cooper AJ, Walkinshaw G, Waters CM (1994) Glutamate-induced apoptosis results in a loss of striatal neurons in the parkinsonian rat. Neuroscience 63 (1):1-5. doi:10.1016/0306-4522(94)90002-7

39. Mura A, Feldon J, Mintz M (2000) The expression of the calcium binding protein calretinin in the rat striatum: effects of dopamine depletion and L-DOPA treatment. Exp Neurol 164 (2):322-332. doi:10.1006/exnr.2000.7441

40. Nikolaus S, Larisch R, Beu M, Forutan F, Vosberg H, Müller-Gärtner HW (2003) Bilateral increase in striatal dopamine D2 receptor density in the 6-hydroxydopamine-lesioned rat: a serial in vivo investigation with small animal PET. European journal of nuclear medicine and molecular imaging 30 (3):390-395. doi:10.1007/s00259-002-1056-2

41. Oorschot DE (2013) The percentage of interneurons in the dorsal striatum of the rat, cat, monkey and human: A critique of the evidence. Basal Ganglia 3 (1):19-24. doi:10.1016/j.baga.2012.11.001

42. Parent A, Cicchetti F, Beach TG (1995) Calretinin-immunoreactive neurons in the human striatum. Brain Res 674 (2):347-351. doi:10.1016/0006-8993(95)00124-9

43. Parent $M$, Parent $A$ (2006) Single-axon tracing study of corticostriatal projections arising from primary motor cortex in primates. J Comp Neurol 496 (2):202-213. doi:10.1002/cne.20925

44. Petryszyn S, Beaulieu JM, Parent A, Parent M (2014) Distribution and morphological characteristics of striatal interneurons expressing calretinin in mice: A comparison with human and nonhuman primates. Journal of chemical neuroanatomy 59-60:51-61. doi:10.1016/j.jchemneu.2014.06.002 
45. Petryszyn S, Di Paolo T, Parent A, Parent M (2016) The number of striatal cholinergic interneurons expressing calretinin is increased in parkinsonian monkeys. Neurobiol Dis 95:46-53. doi:10.1016/j.nbd.2016.07.002

46. Pisani A, Bernardi G, Ding J, Surmeier DJ (2007) Re-emergence of striatal cholinergic interneurons in movement disorders. Trends Neurosci 30 (10):545-553. doi:10.1016/j.tins.2007.07.008

47. Revishchin AV, Okhotin VE, Korochkin LI, Pavlova GV (2010a) A new population of calretinin-positive cells, presumptively neurons, with polymorphous spines in the mouse forebrain. Neurosci Behav Physiol 40 (5):541-552. doi:10.1007/s11055-010-9295-3

48. Revishchin AV, Okhotin VE, Pavlova GV (2010b) New calretinin-positive cells with polymorphous spines in the mouse forebrain during early postnatal ontogeny. Neurosci Behav Physiol 40 (8):833840. doi:10.1007/s11055-010-9349-6

49. Rivera A, Alberti I, Martín AB, Narváez JA, de la Calle A, Moratalla R (2002) Molecular phenotype of rat striatal neurons expressing the dopamine D5 receptor subtype. The European journal of neuroscience 16 (11):2049-2058

50. Rymar VV, Sasseville R, Luk KC, Sadikot AF (2004) Neurogenesis and stereological morphometry of calretinin-immunoreactive GABAergic interneurons of the neostriatum. J Comp Neurol 469 (3):325339. doi:10.1002/cne.11008

51. Schmitz C, Hof PR (2000) Recommendations for straightforward and rigorous methods of counting neurons based on a computer simulation approach. Journal of chemical neuroanatomy 20 (1):93114. doi:10.1016/s0891-0618(00)00066-1

52. Schwaller B (2014) Calretinin: from a "simple" $\mathrm{Ca}(2+)$ buffer to a multifunctional protein implicated in many biological processes. Front Neuroanat 8:3. doi:10.3389/fnana.2014.00003

53. Suarez LM, Solis O, Carames JM, Taravini IR, Solis JM, Murer MG, Moratalla R (2014) L-DOPA treatment selectively restores spine density in dopamine receptor $\mathrm{D} 2$-expressing projection neurons in dyskinetic mice. Biol Psychiatry 75 (9):711-722. doi:10.1016/j.biopsych.2013.05.006

54. Tepper JM, Koos T, Ibanez-Sandoval O, Tecuapetla F, Faust TW, Assous M (2018) Heterogeneity and Diversity of Striatal GABAergic Interneurons: Update 2018. Front Neuroanat 12:91. doi:10.3389/fnana.2018.00091

55. Trouche S, Koren V, Doig NM, Ellender TJ, El-Gaby M, Lopes-Dos-Santos V, Reeve HM, Perestenko PV, Garas FN, Magill PJ, Sharott A, Dupret D (2019) A Hippocampus-Accumbens Tripartite Neuronal Motif Guides Appetitive Memory in Space. Cell 176 (6):1393-1406 e1316. doi:10.1016/j.cell.2018.12.037

56. Unal B, Shah F, Kothari J, Tepper JM (2015) Anatomical and electrophysiological changes in striatal $\mathrm{TH}$ interneurons after loss of the nigrostriatal dopaminergic pathway. Brain structure \& function 220 (1):331-349. doi:10.1007/s00429-013-0658-8

57. Wei B, Nie Y, Li X, Wang C, Ma T, Huang Z, Tian M, Sun C, Cai Y, You Y, Liu F, Yang Z (2011) Emx1expressing neural stem cells in the subventricular zone give rise to new interneurons in the ischemic 
injured striatum. The European journal of neuroscience 33 (5):819-830. doi:10.1111/j.14609568.2010.07570.x

58. Wu Y, Parent A (2000) Striatal interneurons expressing calretinin, parvalbumin or NADPH-diaphorase: a comparative study in the rat, monkey and human. Brain Res 863 (1-2):182-191. doi:10.1016/s00068993(00)02135-1

\section{Figures}

A

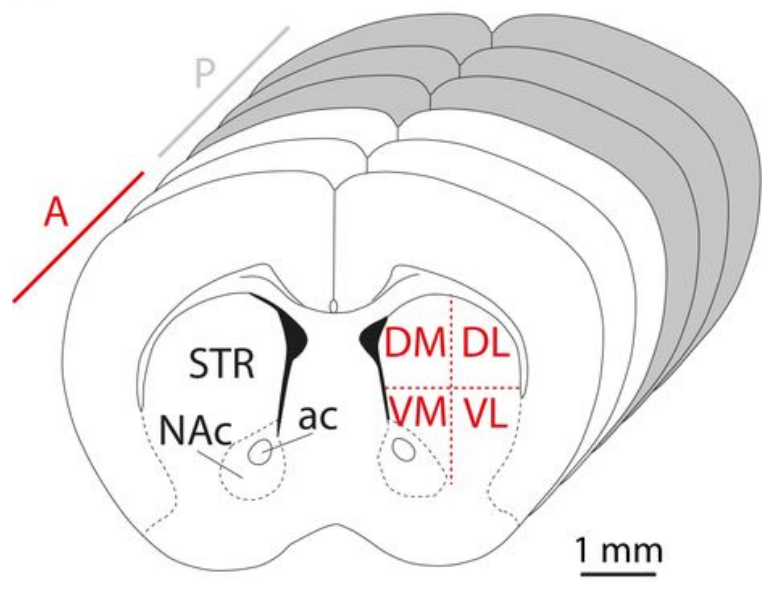

B

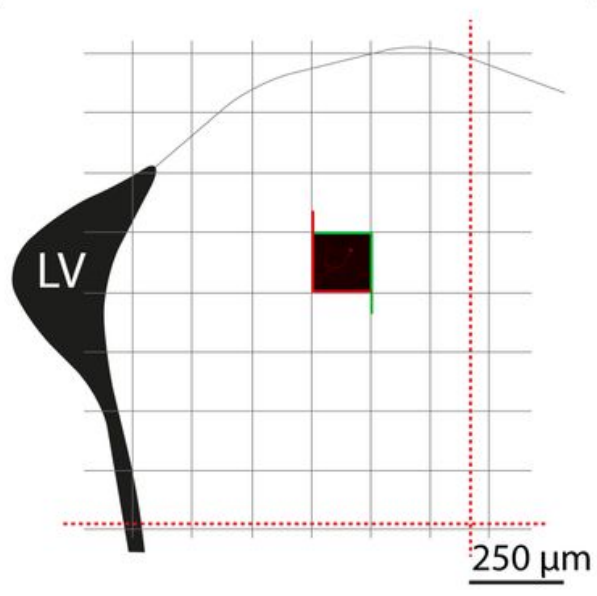

C

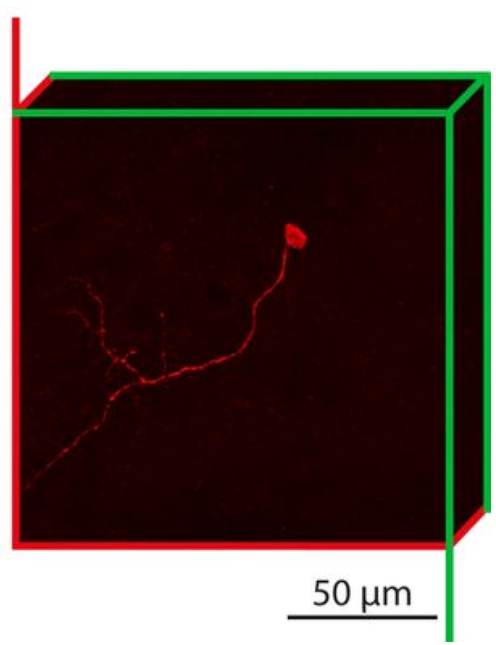

\section{Figure 1}

Method used to estimate the total number of calretinin-immunostained (CR+) cells in different sectors of the mouse striatum using an unbiased stereological approach. A) From 6 equally-spaced coronal sections (600 $\mu \mathrm{m}$ interval), the striatum was divided into 8 sectors: antero-dorso-lateral (ADL), anterodorso-median (ADM), antero-ventro-lateral (AVL), antero-ventro-median (AVM), postero-dorso-lateral $(\mathrm{PDL})$, postero-dorso-median (PDM), postero-ventro-lateral ( $\mathrm{PVL}$ ) and postero-ventro-median (PVM). $\mathrm{B})$ On each of these sectors, a grid formed by $157 \times 157 \mu \mathrm{m}$ squares was randomly positioned. At each intersection of the grid that fell into the sector, a counting frame of the same size was examined, leading to the sampling of the entire striatal sector. $\mathrm{C}$ ) Neurons inside the counting frame that do not contact the exclusion lines were counted whenever their nucleus came into focus within a $12 \mu \mathrm{m}$-thick optical disector centered in the section. 
A

bregma 1.42

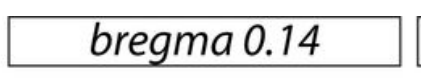

bregma 3.1

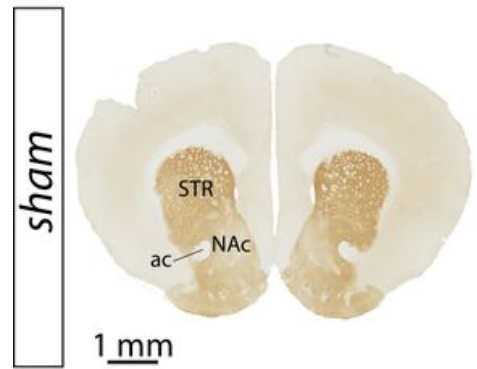

$1 \mathrm{~mm}$

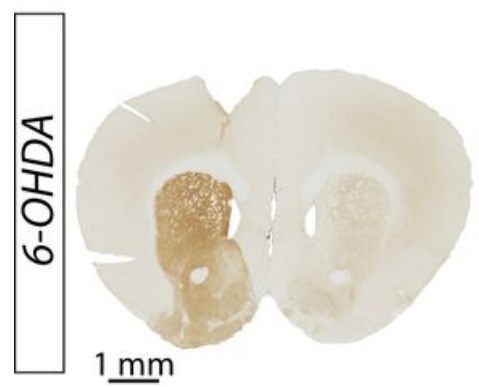

$\underline{1 \mathrm{~mm}}$

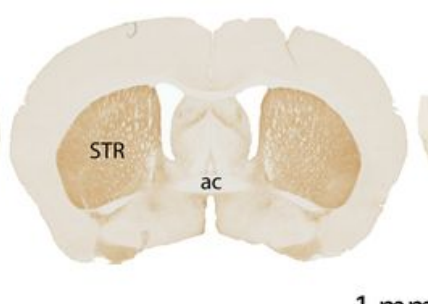

$1 \underline{\mathrm{mm}}$

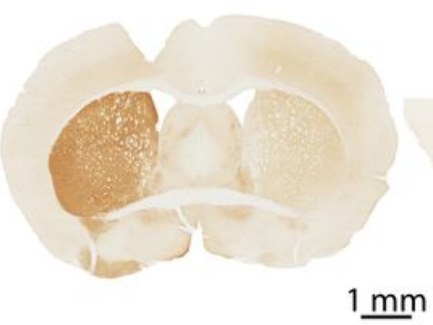

SNC

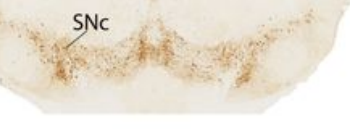

$\underline{1 \mathrm{~mm}}$

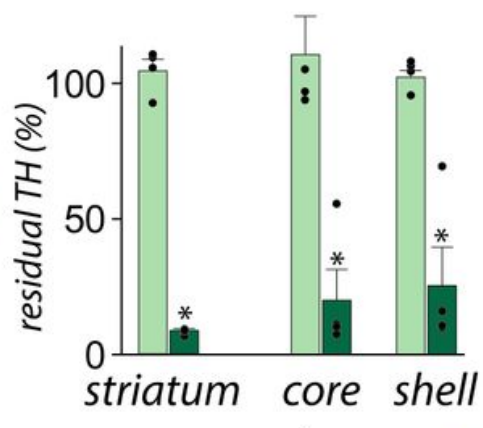

C

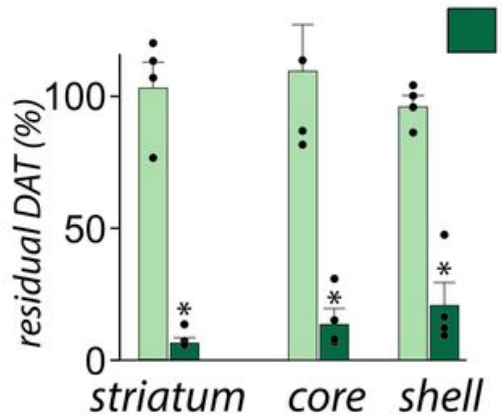

:sham 6-OHDA

Figure 2

Assessment of the dopamine lesion following unilateral 6-OHDA injection in the medial forebrain bundle. A) Coronal sections taken through the striatum (STR, bregma 1.42 and 0.14), the nucleus accumbens (NAc, bregma 1.42) and the substantia nigra pars compacta (SNc, bregma 3.1) were immunostained for tyrosine hydroxylase (TH) in sham (upper row) and 6-OHDA (lower row) lesioned mice. Histograms show TH (B) and dopamine transporter (DAT, C) residual content in the sham (light green) and 6-OHDA (dark green) lesioned striatum as well as in the core and shell compartments of the NAc. Dots represent individual data obtained for each mouse. ${ }^{*} \mathrm{P}<0.05$ for sham vs 6-OHDA-lesioned mice using MannWhitney statistical test. 


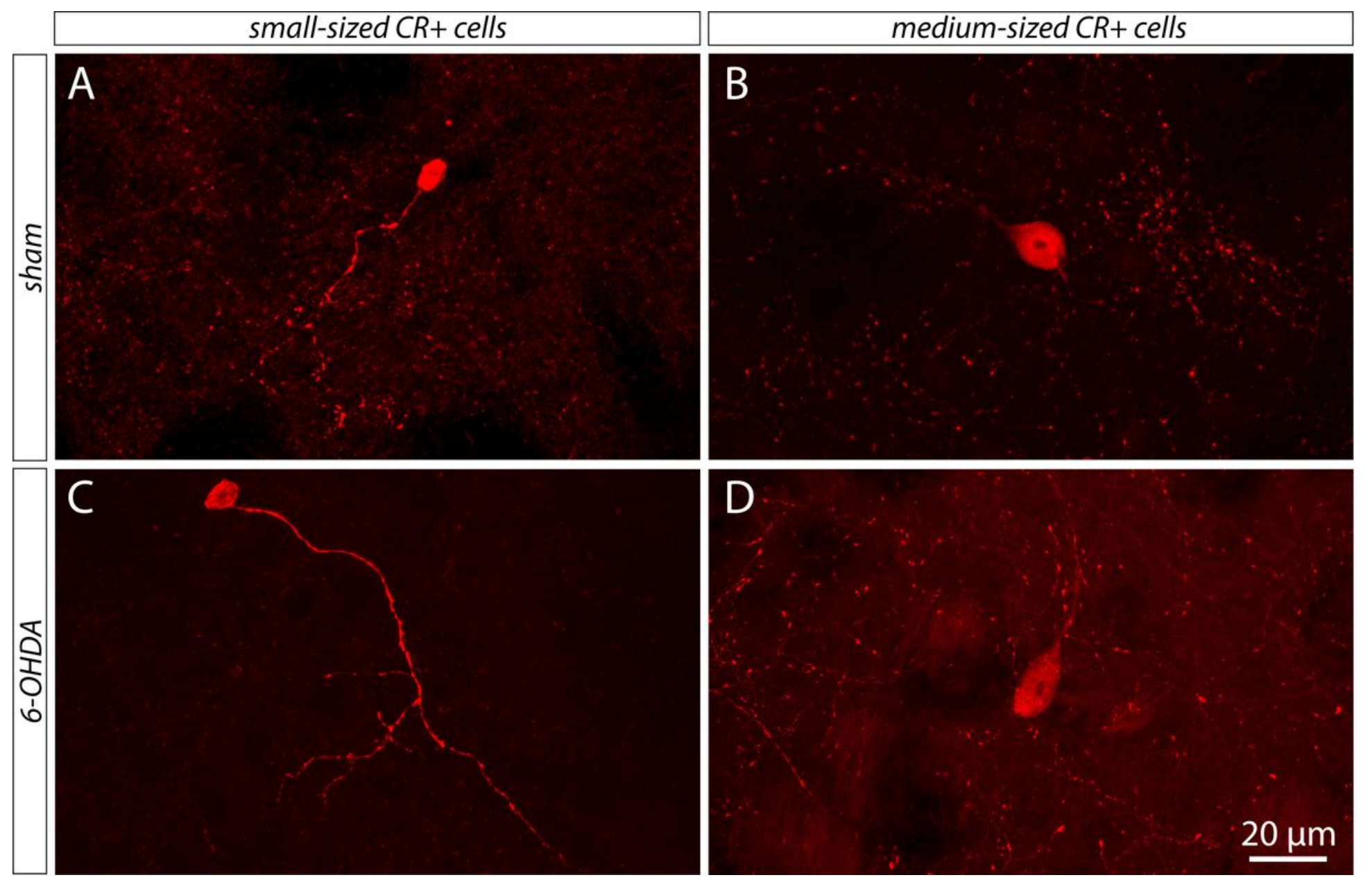

Figure 3

Confocal images of calretinin-immunostained (CR+) interneurons in the sham (A, B) and 6-OHDA (C, D) lesioned striatum. In the striatum of both experimental groups, small-sized $(A, C)$ and medium-sized $(B, D)$ $\mathrm{CR}+$ cells were observed. 


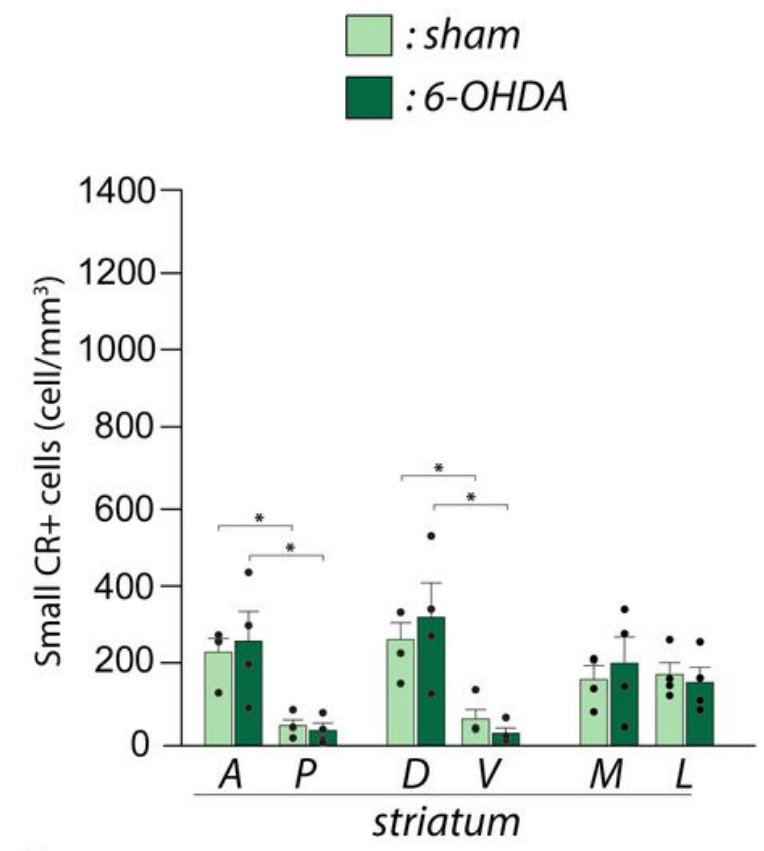

C
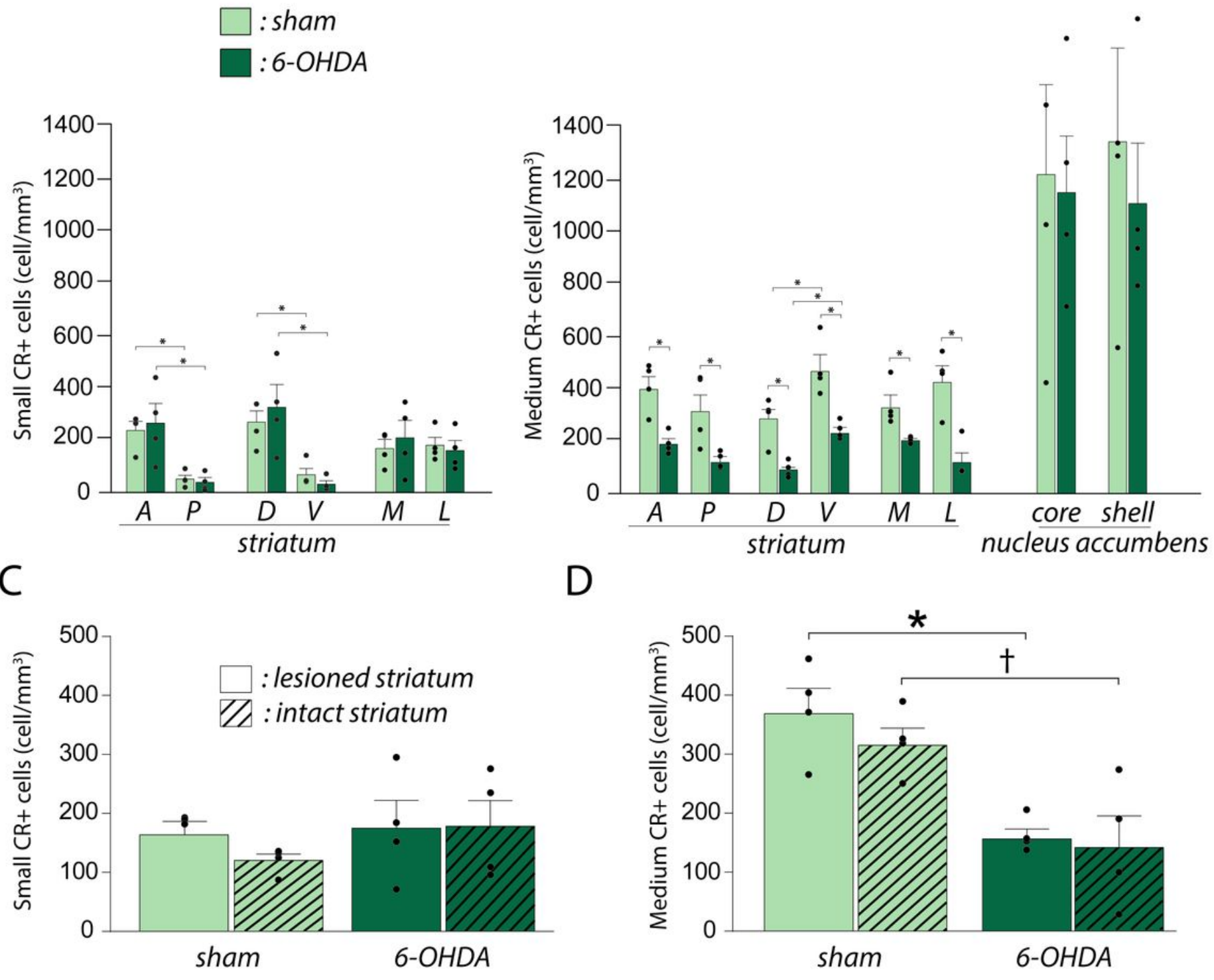

Figure 4

Histograms depicting the density of the small $(A, C)$ and medium (B, D) CR+ cells in different sectors of the sham (light green bars) and 6-OHDA (dark green bars) lesioned striatum and nucleus accumbens. In $\mathrm{C}$ and $\mathrm{D}$, histograms show the density of $\mathrm{CR}+$ interneurons in the whole lesioned (empty bars) and intact (hatched bars) striatum of sham and 6-OHDA-lesioned mice. In the sham and 6-OHDA-lesioned striatum, a significant anteroposterior and dorsoventral decreasing gradient was observed for the small-sized CR+ cells $(A)$ whereas a dorsoventral increasing gradient characterized the medium-sized $C R+$ neurons $(B)$. In contrast to the small-sized $\mathrm{CR}+$ cells, the density of the medium-sized is significantly decreased in all sectors of 6-OHDA-lesioned striatum, but unaffected in the NAc (B). A similar decreasing trend is observed in the intact striatum (D). * $P<0.05, P=0.057$ using two-way ANOVA followed by Tukey multiple comparison test. 

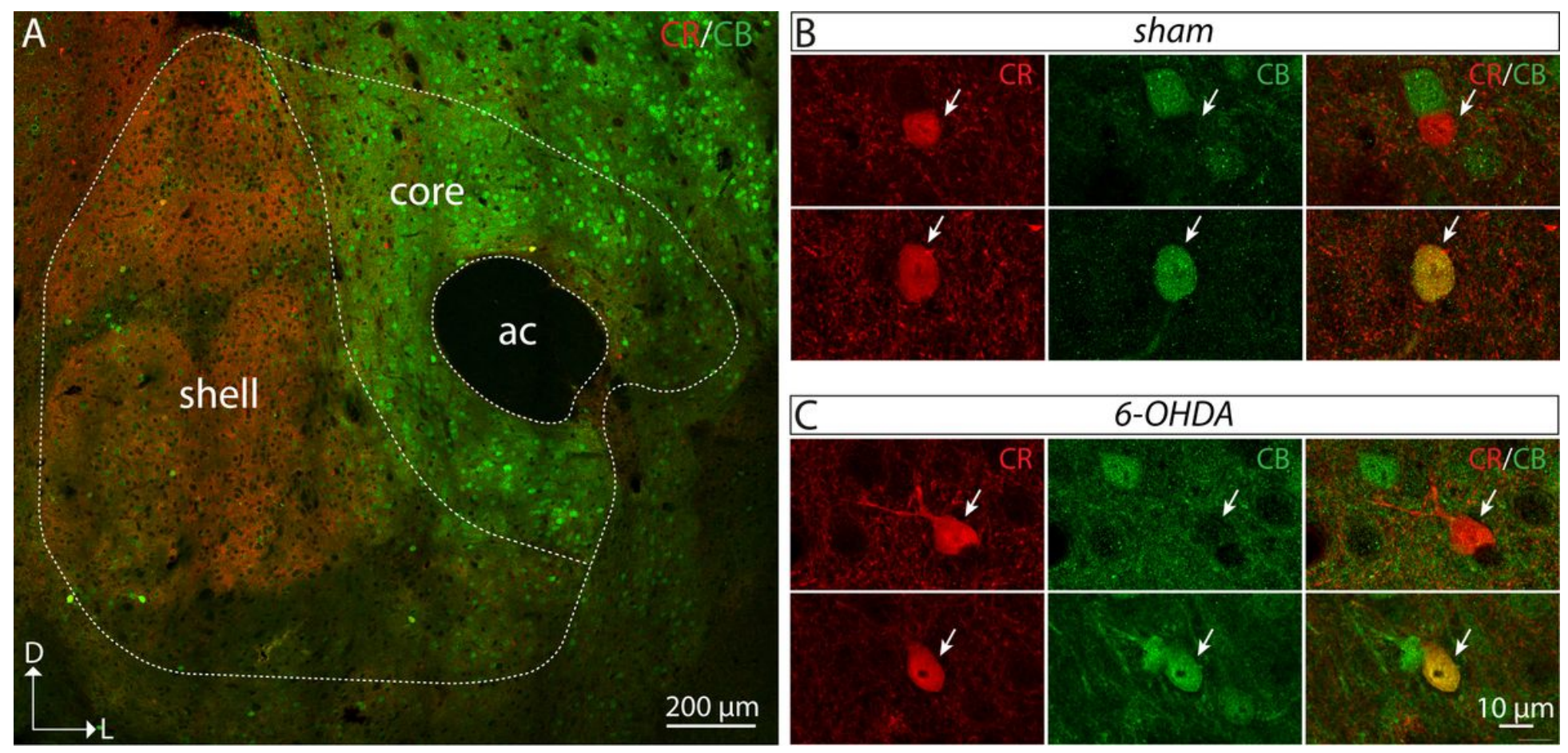

\section{Figure 5}

A) Tile scan of a coronal section doubly stained for calretinin (CR, red) and calbindin (CB, green) used to delineate the core from the shell compartments of the nucleus accumbens (NAc). Confocal images of medium-sized $\mathrm{CR}+$ interneurons observed in the core (upper panels) and the shell (lower panels) compartment of the NAc in the sham (B) and 6-OHDA (C) lesioned mice. No small-sized CR+ interneurons were observed in the NAc. 